\title{
Afro-Latin dance as reconstructive gestural discourse: the figuration philosophy of dance on salsa
}

Joshua M. Hall

To cite this article: Joshua M. Hall (2020): Afro-Latin dance as reconstructive gestural discourse: the figuration philosophy of dance on salsa, Research in Dance Education, DOI: 10.1080/14647893.2020.1805731

To link to this article: https://doi.org/10.1080/14647893.2020.1805731

曲 Published online: 03 Sep 2020.

Submit your article to this journal $\widetilde{ }$

Q View related articles $\sqsubset$

View Crossmark data $\nearrow$ 


\title{
Afro-Latin dance as reconstructive gestural discourse: the figuration philosophy of dance on salsa
}

\author{
Joshua M. Hall iD \\ Department of Philosophy, William Paterson University, Wayne, NJ, USA
}

\begin{abstract}
The Afro-Latin dance known as 'salsa' is a fusion of multiple dances from West Africa, Muslim Spain, enslaved communities in the Caribbean, and the United States. In part due to its global origins, salsa was pivotal in the development of the Figuration philosophy of dance, and for 'dancingwith,' the theoretical method for social justice derived therefrom. In the present article, I apply the completed theory Figuration exclusively to salsa for the first time, after situating the latter in the dance studies literature. My first section explores Juliet McMains' recent history, Spinning Mambo into Salsa, with an emphasis on the dynamics of class, race and sex therein. My second section explores a resonant Afro-Latin dance history, Marta E. Savigliano's Tango and the Political Economy of Passion, where she deploys salsa's sister-dance (tango) as a 'counter-choreography' to the choreography of postmodern neocolonialism. And my third section applies Figuration's four central aspects of dance (or 'Moves') to salsa qua member of its 'societal' family of dance. In conclusion, through partnering with salsa, Figuration emerges as a member of its own 'discursive' family of dance, while salsa emerges as a gestural discourse capable of helping reconstruct a more socially-just world from the postmodern ruins of today.
\end{abstract}

\section{ARTICLE HISTORY}

Received 16 October 2018

Accepted 2 August 2020

\section{KEYWORDS}

Salsa; social justice; Juliet McMains; Figuration; Marta Savigliano

The Figuration philosophy of dance posits four central aspects of dance (called 'Moves'), and applies them to seven 'families' (in Wittgenstein's sense) of dance. Salsa dance, in addition to serving as the running example of Figuration's 'societal' family of dance, is also the unique inspiration for a new social justice-directed theoretical method, 'dancingwith.' But the present article is the first text in which Figuration is applied exclusively to salsa. To set the stage for that analysis, I make two preparatory moves. First, I survey Juliet McMains' celebrated Spinning Mambo into Salsa: Caribbean Dance in Global Commerce, an historical and (participatory) ethnological study of present-day salsa, with an emphasis on the centrality of race and ethnicity (hereafter, following Linda Martín Alcoff, 'ethnorace'), gender and sexuality (hereafter 'sex') and class. ${ }^{1}$ With this empirical data in place, I find a consonant methodology in Marta Savigliano's study of the related Latin dance of tango, namely a channeling of Latin dance's performative power to reconstruct the injustices often exacerbated by today's deconstructing Academy. In conclusion, by thus partnering with salsa, Figuration becomes a 'discursive' dance with salsa's gestural discourse, in joint pursuit of decolonizing, reconstructive justice. 


\section{Salsa as survivor of posmodernism}

In McMains' Introduction to Spinning Salsa into Mambo, she acknowledges the problematic ontological status of salsa dance as an object of academic study, noting that 'little binds some expressions of salsa dance beyond their enjoyment of similar music' (McMains 2015, 1). In fact, she relates that the very name 'salsa' was only 'adopted as a convenient commercial label in the 1970s, largely propelled by Fania Records' (1). ${ }^{2}$ Thus, neither the dance nor the name 'salsa' are natural/authentic. Moreover, the debate continues as to whether 'salsa' and 'mambo' should be interchangeable terms, or instead refer to two discrete dances. What is clear, though, are the identities of several other dances from communities of color that contributed to what is called salsa, including 'African-American jazz,' 'Afro-Cuban mambo,' 'Afro-Cuban son' and 'Afro-Cuban rumba' (1).

Given these influences, McMains' study of salsa dance 'begins during the mambo era of the 1940s and '50s, with flashbacks to the swing and rumba eras that preceded it' (McMains 2015, 1). For the same reason, she situates her study primarily in New York City, which is not only the heart of the U.S. empire, but 'which enjoys such a constant flow of immigration to and from the Antillean islands that it is frequently conceived as part of the Caribbean' (2). As I will explore with Savigliano below, however, this blurring of the imperial center and its periphery on McMains' part risks eliding important postcolonial insights into salsa's history and present.

Digging into salsa's musical origins in the Caribbean, McMains notes that salsa music 'is a hybrid of many Caribbean musical forms - mambo, son, danzón, rumba, bomba, plena - which were themselves syncretisms of Spanish, African and indigenous traditions that shaped Spanish Caribbean culture' (McMains 2015, 2). In short, McMains suggests, 'salsa is perhaps [the] model child' of the phenomenon that ethnomusicologist Antonío Benítez-Rojo calls 'supersyncretism,' which McMains defines as follows: 'a tendency to recombine elements from disparate cultural traditions in such a continual pattern of interruption and repetition that notions of identifying an original source or center fade into absurdity' (2). In short, McMains summarizes, 'not one country or culture can claim [salsa] as their exclusive creation' (2). This point is crucial for the Figuration analysis below of the 'positure' of salsa, which claims that salsa is abyssally hybrid and impure, a dynamic flux of dancing forces rather than an entity with a fixed and authentic historical core.

Overall, McMains identifies three main eras in salsa's history, namely (1) the mambo dance craze in the 1950s, centered at the Palladium Theater in Midtown Manhattan, (2) what she terms the 'kitchen-style salsa' of popular revolt in the 1970s, centered in the streets of the barrios, and (3) the global commercial boom stretching from the 1990s to the present, centered in international 'salsa congresses' and the worldwide web. Of these, I am most concerned here with (2), which McMains notes 'began as a political movement' that 'forged pan-Latino identities through musical expression of shared experience' (McMains 2015, 6). Thus, McMains writes, the changes from (1) to (3) - with the significant exception of (2) in between them - 'lessen the importance of Africanist aesthetics in Latin dance practice,' which can be 'directly traced to the codification of salsa for sale in an international dance industry' (71). 
For her empirical data, McMains draws on 'oral histories with dancers, teachers, DJs, promoters, and musicians of salsa and mambo,' including 'more than 100 interviews between 2006 and 2014' (McMains 2015, 12). To acquire this data, she 'relied extensively on ethnographic methods,' including 'fieldwork at salsa clubs, socials, classes, and congresses,' where she also 'employed participant observation' (16). Particularly significant in this regard is that she conducted what she terms 'physical dialogues with informants' that is, actual real-time social dance partners - which dialogues 'focus on understanding their embodied knowledge,' and which dialogues, McMains writes, 'I consider interviews in another language, one in which my whole body listens' (17). Such dancing dialogues, including my weekly participation at salsa dance events in multiple U.S. cities, also had a significant influence on the final form of Figuration.

With McMains' methodology thus arranged on stage, she turns to the performance of her salsa dance study, beginning with the observation that the mambo dance craze of the 1950s was 'significant for the racial and ethnic integration it engendered,' with 'people of African descent' in particular 'in high attendance' (McMains 2015, 32). Moreover, she adds, 'the majority of patrons, especially the better dancers, were dark-skinned,' as a result of which racial dynamics 'blackness and Latin dancing were closely aligned, at least among the residents of Spanish Harlem' (34). As famed African-American literary artist Amiri Baraka put it, 'In the '50s, if you were black and you were in New York, mambo was what was happening' (Thompson 1973, 41, quoted in McMains 2015, 37). Fortunately, today's racial demographics are even more progressive. 'Modern-day salsa venues,' McMains writes, 'are even more racially integrated that was the Palladium' in the 1950s (44).

Unfortunately, however, what has not survived to the present is that those Africana racial demographics are no longer reflected at the technical level of the dance as well. The mambo, McMains writes, 'shared strong affinities with other African dance forms,' as 'illustrated through application of Africanist aesthetics,' including 'segmented isolation of hips, pelvis, and shoulders; solo improvisation in dialogue with musical rhythms and body shapes that are asymmetric, angular, and idiosyncratic,' among other features (McMains 2015, 35). Today, by contrast, these Africana techniques have been marginalized by, among other phenomena, turn patterns that 'increased exponentially in complexity and speed' and teachers who 'standardized students' relationship to the music much more rigidly than had been done in the mambo era' (125). Moreover, these changes have also had a net negative effect on female salsa dancers, as every sacrifice of independence for formality entails submitting to a system of formality that continues to be under the disproportionate control of men.

There have also been similar negative changes, from the 50s to today, which primarily concern the embodied axis of sex. Most important among the latter, perhaps, is McMains' observation that 'competition, which in Palladium mambo dancing was primarily focused within the partnerships as the male and the female partner tried to impress each other with their own solo moves, has been transformed into competition between men' (McMains 2015, 56). She gives the example, in present-day 'jam circles,' a phenomenon which began as 'the cyphering of b-boying/b-girling where one dancer after another will enter the "cypher" (circle of other b-boys/b-girls) to informally battle' (56). In today's version of these jam circles, by contrast, men 'use a single woman as the vehicle through which to challenge each other,' making the woman 'merely the tool or the 
weapon' of the male dancer (56). This also aligns with Savigliano's analyses below of how male tango dancers have always used female dancers as tools in weapons in their 'homosocial' vying for power, privilege, and wealth (45).

In McMains' chapter dedicated to 70s salsa, or 'salsa' per se (as opposed to 'mambo') she notes that 'Many early salsa fans were second-generation immigrants who, coming of age during or after the Civil Rights Movement, began to question their assimilation into American culture and turned to salsa as a means of reconnecting to their cultural heritage' (McMains 2015, 80). Moreover, 'many of the most popular salsa musicians' of the 70s, McMains notes, 'were self-taught and their playing had a raw and aggressive quality with which salsa audiences identified' (81). In support of this point, McMains cites ethnomusicologist Christopher Washburne's claim that salsa music 'is defined by its association with el pueblo (the people),' symbolizing 'a weapon against social injustice' and featuring lyrics about 'violence, poverty, political consciousness' (81, 82). More generally, McMains adds, 'salsa in the 1970s was more about mobilizing community than about forging individual identity' (85).

As part of this hybrid identity, however, Latinos also mixed into what we now (but they did not then) call 'salsa,' the U.S. American rock 'n roll dance called the 'Hustle' (McMains 2015, 87). In fact, Eddie Torres, the undisputed master of modern salsa, learned to dance by going to clubs and practicing the Hustle with other social dancers (97). As Torres thus institutionalized salsa, however, principally through formal dance classes, there emerged 'a growing rift between studio salsa dancers and those who grew up dancing salsa on the streets or in homes among family and friends' (110). Unsurprisingly, the former group was mostly Anglo, the latter mostly Latino. McMains notes, for example, that the 'recollection of learning to dance in the kitchen with [one's] mother' was a narrative that in her interviews was 'repeated by countless Puerto Ricans, Dominicans, and Cubans' (113). Note also that the control in this tradition was matrilineal, passing from women to sons. Perhaps in part because this informal method is also similar to the way I learned salsa, I enthusiastically share this 70 s perspective, which undoubtedly helped shaped the Figuration analysis of salsa below.

\section{Latin dance as counter-choreography to postmodern colonizing}

To recapitulate McMains' analysis, the specter of ethnoracism (along with the specters of classism and sexism) haunts the entirety of salsa's history, from its mambo origins until today. So too, according to Savigliano, goes salsa's sister Latin dance of tango. Tango and the Political Economy of Passion is an immensely rich text, with many divergent threads, but I will deploy it here in the same way that she admits deploying other theoretical texts: namely, as a strategic tool, exploited for what it can contribute to a personal and political reconstructive dance of decolonization (Savigliano 1995, 15). ${ }^{3}$ Beginning as she does, with the personal, I was surprised to find myself - given the massive geographical and embodied differences between Savigliano as an Argentinian Latina and myself as an Alabamian Anglo - involuntarily identifying with her autobiographical opening narrative. That is, though there are of course many important differences between our respective homes, I was born and raised in the domestic borderland/periphery of the U. S. American empire, specifically in the repeatedly colonized Deep South state of Alabama. 
The colony of Alabama, begun as the westward expansion of the penal colony of Georgia, quickly developed into a colonial slave society, until it was occupied during Reconstruction by the justifiable colonizing force of The Freedman's Bureau, and it remains the subject of universal ridicule throughout the country, demeaned with labels such as 'backwards' and 'ignorant.' Like Argentina, Alabama has also been populated, since its founding, with an overlapping succession of ethnoracially undesirable peoples, from the Creek and Choctaw Native American tribes inhabiting the land at the time of European colonization, to the Africans kidnapped to work enslaved on that land, to today's considerable Latinx population.

Like Savigliano, when I first moved to the North (in my case, Pennsylvania for graduate school in 2003, followed by New York in 2016), I encountered negative stereotypes of Southerners, and felt a powerful sense of exile, nonbelonging, and nostalgia for my broken, racially and ethnically diverse, poor, and deeply politically and economically corrupt home, including for the practice of its folk dances (including the folk dance of the Appalachian people, called 'clogging,' which had danced since age twelve, and salsa later in my teens). 'On a personal level,' Savigliano writes on the first page of her Preface, 'it is more common for any argentino living abroad to connect the experience of longing and nostalgia to the tango' (Savigliano 1995, xiii). In the North of the U.S. for me, like Hawai'i for Savigliano, Latin dancing taught in tightknit familial settings became viscerally connected to a feeling of home, which became the first inspiration for writing about that dance, despite having danced it for years in the colonial setting.

Finally, on this note of resonantly colonial origins, Alabama's clogging and salsa, just like Argentina's tango, began with black folks. 'The Sociedades de Negros [Societies of Blacks],' Savigliano writes, 'associated with the origins of the tango in the Río de la Plata region, re-created the rhythms and ombligadas of the African enslaved exiles' (Savigliano 1995, xiv). As noted above in McMains, salsa is an Afro-Caribbean dance traceable to black dances from West African (and clogging is a fusion of Appalachian Irish dance and African-American tap dance). Thus, as McMains claims for salsa, Savigliano claims for tango as follows: 'Race, class, ethnic, and erotic exiles cut tango through and through from its very roots' (xiv). Thus, Alabama clogging and salsa, like Argentine tango, constitute a 'story of encounters between those who should never have met,' 'impossible but fatal' encounters in which 'black and white, rich and poor, men and women, colonizer and colonized - each is brought much too close to the other' (xv).

Coming from these colonial origins, Savigliano's primary concern (similar to McMains' with salsa, but differently-positioned geopolitically), is the global colonial market for the 'Passion' of the exoticized, colonized 'Others,' including women of color (Latinas and other) tango dancers (Savigliano 1995, 2). Crucially, this position of passion, according to Savigliano, is also one of agency. As this is also true of salsa for Figuration, what Savigliano writes about the role of the Latin dance of tango as also holds for salsa . To wit, the Latin dance is not an example, it is the main ingredient in this exercise of decolonization ... corporealized in the specificity of sweaty, sensual, fully efforted bodies' (4). Put in Figuration's terms, the project is not to use philosophy to illuminate salsa, but rather to partner salsa to it, in a discursive dance that transforms philosophy through the energetic movements of salseras' bodies (including mine). ${ }^{4}$

Savigliano's analysis of tango as both 'deconstructive and reconstructive,' in relation to injustices within and without the colony, also applies to salsa for Figuration (Savigliano 
$1995,4)$. Tango, Savigliano writes, is 'a patriarchal and hegemonic representative of my country in that it privileges the popular culture of the urban centers 'over the rest of the provinces and the protagonist role of men over women' (4). In other words, despite tango is simultaneously (1) a tool for reconstructing a decolonized Argentina, and (2) a weapon for the attempts of disempowered Argentinians (including rural people and women) to rectify power imbalances within Argentina.

Savigliano's incorporation of theatrical 'scenes' of imagined dance performances into her analysis is also resonant with Figuration's analysis of salsa. The central and most oftrecurring character in Savigliano's dance scenes (and the character who seems closest to Savigliano's own subject position) is initially introduced as 'the Choreocritic,' or dance critic (Savigliano 1995, 10). One advantage of this performance-based approach is that it buttresses her claim that the 'tango I invoke in these pages is nothing but my own version of tango,' specifically 'an appropriated tango (to which I feel entitled) that disrespectfully challenges the main existing legitimate versions' (12). That is, her inclusion of dance performance scenes is a reminder that her entire text, like the Latin dance on which it is based, is an implicit performance, too.

Savigliano then defines the purpose of her latter, meta-performance, namely 'decolonization.' She then defines the concept as follows: 'learning/unlearning the preeminence of the abstract, totalizing Enlightenment logics over bodies and their absurd techniques of survival' (Savigliano 1995, 13). As an example of decolonization, Savigliano shares the following personal account:

Because I have no answers to my questions, I tango. I tango because I have to move in the midst of these uncertainties. And because I need to show myself and others that I can still move (Savigliano 1995, 16).

This passage also holds true for me, if one merely substitutes 'salsa' for 'tango.' Like tango for her, salsa for me is 'solid because it is the only place in which I feel comfortable restless but at home,' despite the significant differences in our colonized homes (Savigliano 1995, 16). For me, too, the Latin dance in question is 'my strategic language,' despite the fact that our respective relationships to these strategic dance languages are not the same, either. In both cases, however, I find resonances that are sufficiently strong to motivate an allied effort on my part at decolonization, particularly for the poor brown folks in my home colony of Alabama.

Continuing with the theme of Latin dance as language, Savigliano describes (quoting tango theorist Vicente Ross' Things of Blacks) 'the "suspicion" that "feet scribble" the music on the dance floor' when dancers perform the tango (Ross 1958, 117, quoted in Savigliano 1995, 41). Another example of tango as linguistic performance appears in the 'scene' wherein the tango dancer characters 'display discomfort with the Choreocritic's analysis, turn their backs to the audience, and perform grotesque movements,' and thus 'challenge and question the Choreocritic's words with gestures, comments, and hissing' (Savigliano 1995, 52). Note that Savigliano thus gives the gestural language of the dance a position on the stage equal to verbal and textual language, by which the dance language is empowered to co-create with the theoretical language of the Choreocritic. In this way, zooming out to the meta-level of Savigliano's text as a whole, she empowers this Latin dance of tango to engage discursively with the Anglo dance of postmodern theory, through the transformative effects of both dances on her body and the bodies of others. 
These tensions involved in this Latin dancing language appear even higher and more complex in the middle of Savigliano's text. In a new 'scene,' the Choreocritic acquires a new epithet, 'Milonguita,' or female dancer of the milonga style of tango. On the surface, this would appear to be because, for the first time in one of these performance asides, the Choreocritic not only verbalizes theory in the presence of others who dance, but also herself performs the gestural language of dance, albeit reluctantly (Savigliano 1995, 73). At the level of tango's contested identities, moreover, it perhaps suggests a move toward the decolonizing of the Choreocritic, insofar as she now identifies equally with the colonized subjects of Argentinian dancers and the colonizer subjects of Anglo critics. This dancing dialogue scene, between the 'Choreocritic/Milonguita' and a male partner, includes several aspects worth noting (73).

For one thing, the dance is accompanied by the 'Choreocritic's voice on tape, "reading" her text,' which means that she is literally separated from her own body, and her own language. Or, more precisely, her body and language are split in two, both temporally and spatially, with her verbal body in a recorded past, and her gestural body in a living present (Savigliano 1995, 78). A second important aspect of this dance scene is the Choreocritic/ Milonguita's observation that its 'dancing couple' (of which she is one partner) 'will not clarify the issue' as to whether the male partner 'instigates her passion' (or if, instead, it is 'precisely her suggestive hips and footwork that provoke his desire') (78). In addition to this tense ambiguity between the partners in this dance conversation, the Choreocritic/ Milonguita then identifies another level of tense ambiguity within the bodily segments of each partner. 'Their torsos show agreement, their faces fatalism' she intones on the recorded tape, but 'from their waists down, struggle' (78). Further, the Choreocritic/ Milonguita adds, the 'movements of la Otra, her display of resistance/difference, provoke and constantly reshape his Identity,' while the female partner's identity, by contrast, 'is a colonized identity born to be unfulfilled' (78). At the end of this dance-within-a-dance scene, finally, the two dancers 'bow for the audience, proud, arrogant, 'distinguished' (82). Perhaps this is to suggest that the Choreocritic/Milonguita has also, as La Moreira before her, been seduced by dancing to the music of her theory (82).

On that subject, the first two sections of the last chapter of Savigliano's text constitute her own oppressed, colonized, and decolonizing cry. She describes those sections as 'autobiographical fictions,' and identifies them as 'the marrow of this book, my "motives" all along' (Savigliano 1995, 221). These sections are also the most resonant with the Figuration analysis of salsa below. The first of Savigliano's two sections describes her experience of learning to dance from her grandfather, reminiscent of McMains' interviewees' stories of 'kitchen-style salsa' lessons from their mothers. Savigliano's grandfather, Don Beto, was able to teach her because, like 'many argentino men of his generation, his steps were drawn to the crossing of boundaries,' including those between respectable society and the tango demimonde (208). Even though such 'middle-class men frequently broke the rule of avoiding the tango environment,' Savigliano notes earlier in the book, their 'adventurous moves across class and moral boundaries did not, however, call into question the boundaries per se' (137). This fact is also amply illustrated by McMains' salsa history, which reveals many borderlanders and boundary-crossings that leave their boundaries fully intact.

Savigliano then returns to the theme of Latin dance as language, describing Don Beto's crossings in linguistic terms. 'For him,' she writes, 'all women were blank pages on which 
to write his story' (Savigliano 1995, 208). Returning to her theme of women's strategic empowerment through and despite tango, Savigliano adds that the male Latin dancer eventually 'witnesses, horrified, how the blank, inert pages on which he was writing his story grow an irregular thickness of their own. Women's bodies are, actually, docile bodies in rebellion' (209). Such is clearly also the case for Savigliano herself as author, as manifested in the defiant choreography of her manuscript, composed in the adulthood following her childhood lessons in the choreography of tango.

Her agency thus foregrounded, in the second section Savigliano offers what she calls 'a twisted ethnography of postmodernism in which postmodernism stands for the culture of late, postindustrial capitalism and for [its] paradigmatic philosophy' (Savigliano 1995, 211). In short, 'Tangoing a passionate counterspell,' with which Savigliano 'intend[s] to reverse postmodernism's curse' (212). Or, as I wish to suggest, her work could be understood as a 'counter-choreography,' as suggested by her subsequent rebranding of the postmodern 'curse' as a choreographed dance. 'Postmodernism asks us,' Savigliano explains, 'to dance, intensely, a fantastic choreography rendered in the genre of horrorfiction' (213). And though she accepts this horrific request, she does so with her own defiant twist. 'Like a milonguita,' she declares, 'I follow the steps of my postmodern partner, and I resist' (213). More specifically, in her subsequent section, Savigliano explains that the preceding two sections were merely 'parodic reconstructions' and 'attempts at unlearning' (221). She even goes so far as to refer to her 'attack' on postmodernism in scare quotes (223). In other words, the preceding section was a strategic performance, a counter-choreography to the colonizing choreography that she finds in postmodernism.

Postmodernism is also, however, a dance for Savigliano, and a partner dance, which as such can never completely eliminate the agency of the follower, since without both agencies the partnership and its dance become deathly still. 'Tangoing through postmodernism,' Savigliano concludes defiantly, taking full advantage of this agency, 'I perform my awkward decolonizing kicks in the midst of that patriarchal and colonial dance. There are no other dances available for me' (Savigliano 1995, 226).

\section{Salsa as vanguard of reconstruction}

There is, fortunately, at least one more dance for me. Figuration took its first steps from the general acknowledgment that dance is widely neglected in the history of canonical Western philosophy (the only partial exceptions being Plato and Nietzsche). Given this absence, Figuration proceeded in two stages. First, I performed a phenomenological analysis of my own seventeen years of dance experience (including sixteen with salsa specifically) to generate a small cluster of concepts that could be considered central aspects of dance. Second, I went back to the canonical philosophers who neglected dance and looked instead for one of these concepts in their work. The idea was - given the impossibility of writing a history of the philosophy of dance based on philosophers' analyses of dance as such - to produce a history of the philosophy of dance derived from philosophers' analyses of phenomenologically-generated core concepts of dance.

I termed these central constructs or aspects of dance 'Moves,' named them 'positure,' 'gesture,' 'grace' and 'resilience,' and narrowed my focus to the three most distinctive 
conceptions of the four 'Moves' in the history of Western philosophy. The result was four three-part conceptions, which I will now briefly summarize. First, by 'positure,' I mean 'the dynamic imitation of stasis.' The point here is that any living animal, even when not obviously moving, is always covertly moving, at least internally, in the process of maintaining the appearance of rest. Second, by 'gesture,' I mean 'the carrying-across funding language.' With this strange word-formation I am attempting to suggest the etymological meaning of gesture ('to carry across') insofar as all gesture, including linguistic gesture, is both 'funded' (or invested by) and 'founded' (or created on the basis of) the movements of bodies. Third, by 'grace' I mean 'a pleasing figure/ground reversal.' The figure and ground here are the organism and its environment, respectively, because in consummately graceful movement, the environment seems to move seamlessly through the organism. And fourth, by 'resilience' I mean 'a flourishing recirculation.' I am attempting to suggest resilience's etymological meaning of 'leaping back' or 'jumping again' - in part because it foreground's its definition as always springing back into shape, always ready for more, persisting through time's deformations.

Having thus constructed the four Moves, I then applied them to what I term the seven 'families' of dance. By 'families' here, I am attempting to channel Wittgenstein's concept of 'family resemblances,' which he never, to the best of my knowledge, applied to dance. Wittgenstein uses the phrase 'family resemblances' to refer to named phenomena (his preferred example being 'games') that appear impossible to define with a complete list of necessary and sufficient conditions, but that can nevertheless be pragmatically understood as constituting a family, in the sense that each of its 'family members' possesses what are deemed a sufficient number of traits that are common in that family. ${ }^{5}$ Connecting this back to dance, language too for Wittgenstein consists of a family of different games, or 'language games,' which translates the German word Sprachspiele, the root of which (spiele) according to philosopher Hans-Georg Gadamer, 'originally meant "dance," and is still found in many word forms' (Gadamer 2004, 2). Thus, one could also translate Sprachspiele's 'language games' as 'language dances.' In this sense, there does not exist a unified thing called 'dance,' but instead a family of phenomena which are meaningfully related through a cluster of shared similarities. It is important to note, however, that my own attempt at naming these seven family members of dance represents merely one provisional grouping. I make no claim to comprehensiveness, finality, or the best possible names for the families I have attempted to identify. ${ }^{6}$ With that proviso in mind, I turn to Figuration's 'societal' family of dances, and to its member name 'salsa.'

\section{Positure}

Synthesizing my etymological analyses, from the larger project of Figuration, of Nietzsche's The Gay Science and Aristotle's On Generation and Corruption, Physics and On the Soul, and my conceptual analyses of Aristotle's Categories and Plato's Laws, resulted in the following definition of the first Move, positure: 'poetically creative, politically situated, dynamic imitation of stasis.' To condense my analyses from the larger project, positure is poetically creative because of its kinship to poetry via its character of positing reality (Nietzsche). Positure is politically situated because all movement takes place within a community with which it is reciprocally determining (Plato). And positure is a dynamic imitation of stasis because both philosophical accounts of the world and the 
world itself are constant activities that only appear to be a static collection of stable things or objects (Aristotle). The critical dimension of positure for philosophy is its claim that anything taken to be completely static and secure is in fact a dynamic process that merely gives the appearance of immobility.

I will now show how this critical function plays out in actual analyses of salsa. For all four Moves, I will begin my analysis with the conventional or commonsensical usage of the Move, then consider the two adjectival aspects and the one substantive core of the amplified, philosophical construct. In the case of positure, the commonsense meaning is posture or position, the first amplified aspect is poetic creativity, the second amplified aspect is political situatedness, and the substantial core is the dynamic imitation of stasis. For salsa, the commonsensical posture or position is of an apparently simultaneously rigid and comfortable 'dance frame' created by the bodies of two partners which are nevertheless relaxed enough to allow for the extensive and sinuous hip movements that accompany the basic steps of the dance. Positure finds poetic creativity in salsa's ability to sustain in each couple a constant romantic and/or sexual tension that never (a) finds full release or expression, (b) spills over problematically to other couples, (c) fades into boredom and weariness, or (d) abandons the music that is its central inspiration and controlling source. Political situatedness can be found in the fact that contemporary salsa dance in the United States is what McMains above identifies as a 'sypersyncretism' of dances from West Africa, (especially Muslim) Spain, the enslaved cultures of the Caribbean Islands, and the United States (especially New York). Moreover, salsa dance is one of few aspects of Afro-Latin culture that has received significant respect and enthusiasm from white America despite concerns over the alleged sensuality of the dance. And dynamic imitation of stasis in salsa lies in the fact that the apparently spontaneous improvisation of moves on the dance floor, often between strangers who have never danced with each other before, is the result of many hours of practice to learn common moves and train the body to guide and/or be guided by unfamiliar physical cues or 'leads.' Though, as McMains observes, there is much less creativity and improvisation in salsa today than in either its mambo heyday in the 50 s or the politically conscious dance of the 70 s.

\section{Gesture}

Synthesizing my etymological analyses of Kristeva's Poetic Revolution in Language and my conceptual analyses of Kristeva's 'Gesture: Communication or Practice?', Condillac's Essay on the Origin of Human Language and Mead's Mind Self, and Society, resulted in the following definition of gesture: 'border-organizing, sympathy-manipulating, funding language.' To condense the insights developed in the larger project, gesture is borderorganizing because of choreography's connections to the chora as that which carries the semiotic aspect of language into the symbolic aspect (Kristeva). Gesture is sympathymanipulating because it is an organism's use or exploitation of the shared manipulations that are the conditions of its being (Mead). And gesture is funding-and-founding language insofar as it is the historical and developmental arche of verbal language (Condillac). Relating this second Move to the first, with gesture and positure Figuration is one-half complete, having identified the primary activity that takes place on its poetic and dynamic basis - namely, the carrying out, in various senses, of 
communication. The critical dimension of gesture for philosophy is the claim that any non-spatial and immaterial communication is always already carried out via spatial and material support.

As for how this critical function plays out in actual analyses of salsa, the commonsense meaning of gesture is a significant movement used to communicate something to an observer, the first amplified aspect is border-organization, the second amplified aspect is sympathy-manipulation, and the substantive core is funding language. For salsa, the commonsensical gestures are the ways the extremities of the body move during the execution of formalized steps. Gesture finds border-organization in salsa's distillation of abstract ways of relating to the other that can be instantiated with an indefinitely large variety of partners. Sympathy-manipulation can be found in the fact that every move is made by attempting to imagine what would elicit a positive and energetic response from one's partner, but is presented as something which is done effortlessly and for one's own sake. And fundingfounding language in salsa lies in the fact that even though the most impressive moves appear as dynamically-evolving, non-human lines and shapes, these moves are all produced by the elaborate interconnection of individual raced, sexed, classed, etc. bodies.

\section{Grace}

Synthesizing my etymological analyses of Schiller's On the Aesthetic Education of Man, Kallias or Concerning Beauty and On Nä̈ve and Sentimental Poetry and Dewey's Art as Experience, along with my conceptual analyses of Avicenna's Metaphysics of the Healing, resulted in the following definition of grace: 'superabundantly playful, figure/ground reversing, meta-human gifting.' To condense the insights from my larger project, grace is superabundantly playful insofar as grace has to do with living shape, or beauty, which is the object of the play impulse (Schiller). Grace is figure/ground reversing insofar as it is the result of an organism-as-figure adapting so perfectly to its environment-as-ground that the latter seems to be moving through the former instead of vice-versa (Dewey). Finally, grace is meta-human gifting insofar as it is the mark of the celestial beings, who give the terrestrial world their sacred revelations through divine revolutions around the godhead (Avicenna). With grace, Figuration is three-fourths complete, and has addressed the manners, styles or qualities of its carryings-out of communication on its poetic and dynamic basis. The critical dimension of grace for philosophy is its claim that the aesthetic dimension of an activity always involves transgressing the integrity of the human. More specifically, that which is transgressed includes (a) seriousness and gravity, (b) the physical boundaries with the environment, and (c) the metaphysical boundaries with the opposing poles of the animalistic and the divine.

As for how this critical function plays out in actual analyses of salsa, the commonsense meaning of grace is an aesthetically pleasing and seemingly effortless quality of movement, the first amplified aspect is superabundant playfulness, the second amplified aspect is figure/ground reversal, and the substantive core is meta-human gifting. For salsa, commonsensical grace is the smoothness with which bodies move individually, in partnership, and in communal manipulations of space. Grace finds superabundant playfulness in salsa's redeploying of erotic, romantic, and athletic skill sets in a public space dedicated to intimate entertainment. Figure/ground reversal can be found in the fact that such skillful movements, which normally work best by appearing effortless and 
self-effacing (in actual courtship, seduction, and athletic competition) are here the phenomena behind which the dancers attempt to suppress their complex individuality. And meta-human gifting in salsa lies in the fact that the best dancing requires both surrender to one's animal instincts and also offering up one's own finite body to godlike ideals of beauty and prowess.

\section{Resilience}

Synthesizing my etymological analyses of Fanon's Black Skin, White Masks and The Wretched of the Earth and my conceptual analyses of Deleuze and Guattari's AntiOedipus and Butler's 'Gender is Burning,' resulted in the following definition of resilience: 'aesthetically militant, madness-impersonating, flourishing recirculation.' To condense the insights elaborated in my larger project, resilience is aesthetically militant because it is a constant combat against violent and oppressive forces (Fanon). Resilience is madness-impersonating in that it taps into a relentless, schizophrenic energy directed against late capitalist norms (Deleuze and Guattari). And resilience is a flourishing recirculation in that it finds well-being in accepting, while constantly modifying, the circular nature of both itself and reality (Butler). With resilience, Figuration is complete, having addressed the temporality, of the styles, of the carryings-out of communication, on its dynamic, poetic basis. The critical dimension of this final aspect of Figuration for philosophy is its claim that no analysis of a practice or discourse is complete without taking into account the temporality and historicity thereof.

As for how this critical function plays out in actual analyses of salsa, the commonsense meaning of resilience, the commonsense meaning is the ability to continually rebound from hardships, the first amplified aspect is aesthetic militancy, the second amplified aspect is madness-impersonation, and the substantial core is flourishing recirculation. For salsa, commonsensical resilience is the discipline required to recreate the (genuine or fabricated) harmony between the partners (and among different groups in attendance) by means of a variety of songs, genres, tempos, styles, etc. Resilience finds aesthetic militancy in salsa's ability to sustain in each partner (and in each raced, classes, etc. group) a kind of war for control and dominance, as so masterfully illustrated by Savigliano in the case of tango. Madness-impersonation can be found in the ability/willingness of the couple to fabricate sexual/romantic tension with a stranger, friend, or relative and/or remain on the precipice of romantic and sexual surrender each time a new song is played. And flourishing recirculation in salsa lies in how the repetition of similar moves to similar songs with similar persons on similar evenings nevertheless creates buoyancy for the societies in which it takes place.

\section{Conclusion}

I will now highlight what I find to be the most important insight into salsa granted by each of the four Moves. First, from positure, the foundation of salsa lies in hybridity and fusion, both of which concepts inherently imply temporality, historicity, place, and context. In other words, Figuration reminds us, through positure, that there is no transhistorical essence or original purity for salsa, despite what many in the community whom McMains interviewed claim. Second, from gesture, dancing interactions in salsa require 
an endless modification of allegedly formal moves, the quality of which is determined by the degree to which those modifications manifest an effective imagining of the desires of one's partners. In other words, Figuration claims, through gesture, that the competence of each salsa performance derives - not from an independent, abstract set of formal movements - but rather from the ability to imagine the singular desires of one's unique partner. Third, from grace, salsa provides a creative template for how to bridge the divides between (a) the private and public spheres, (b) the erotic and the platonic, and (c) sporting and nonathletic interaction, one significant benefit of which is a more holistically, satisfactorily-interconnected body, psyche, and society. In other words, Figuration reveals, through grace, that salsa constitutes a meaningful source for the solution of nondancing psychological and sociopolitical problems. Finally, from resilience, salsa constitutes a kind of natural laboratory for the distress and dysfunction involved in renegotiating raced, sexed, and other embodied power dynamics in our society. In other words, Figuration illuminates, through resilience, as McMains and Savigliano also do in their own ways, that the war for racial, sexual, etc. control is ongoing, and fought on many fronts that might initially appear, from a distance, peaceful.

To summarize this in terms of my previous analyses of McMains and Savigliano, Figuration began as a postmodern deconstructive theory, but in being applied as a whole to salsa dances, Figuration's concepts were torsioned in a reconstructive direction, in the process of trying to do justice to the raced, sexed, classed, etc. dancing bodies of today's colonized globe. In terms of McMains' analyses of salsa, Figuration illuminates the sources of dance's continuing racism and classism under today's global capitalism, and it in terms of Savigliano's analyses of tango, it offers a sketch of a reconstructive program for overcoming the colonialism with which deconstruction has become complicit. In short, by choreographing these pairs of movements together, I have attempted a performance of salsa-empowered-Figuration-empowering-salsa, by embracing salsa's gestural discourse and Figuration's discursive dance.

More concretely, as dancing partner with salsa, Figuration suggests four psychological and four political prerequisites for ideal flourishing (where 'ideal flourishing' is understood as necessarily inclusive of dance flourishing). These requisites are the minimum conditions under which it seems probable that an individual or a community could fully support dance. And by 'fully support,' I mean the absence of obstacles to, as well as the presence of facilitators of, every community member's ability to engage in dance practices of his or her choosing. One example of such an obstacle, and a common one in this culture, is a parent's decision that his or her son should not be allowed to dance because dance is too effeminate and might incline him to homosexuality. Another example would be the recent decision of a principal in Mississippi to cancel a junior high prom (and thereby prevent the occurrence of dancing) because one of the school's students expressed the intention of bringing her lesbian partner to the dance.

I will now briefly re-summarize these conditions for the individual (psychological) and then the community (political). For individuals, positure suggests that they perpetually move and change, and it thus requires a psychological preparedness for change and capacity to adapt flexibly. Gesture suggests that psychological health requires physical health, and thus requires bodily stimulation and discipline. Grace suggests that permeability to the environment is beneficial, and thus requires the promotion of environments with which fusion is desirable. And resilience suggests that cycles and patterns will always 
be repeated, and thus requires a tolerance of repetition and compulsion per se, though not of any particular form thereof.

For communities, positure suggests that stability is a function of tolerating perpetual and shifting tensions, and thus requires societal tolerance at the fundamental level of human embodiment. Gesture suggests that both nonverbal and verbal forms of linguistic expression are crucial release valves for bodily drives, and thus requires that society protect its citizens' freedom of both nonverbal and verbal expression. Grace suggests that aesthetic flourishing requires an open and holistic comportment to one's borders, and thus requires that a society not compartmentalize and/or neglect the aesthetic aspects of life. And resilience suggests that, given that a resurgence of dangers (including dangers from within) is inevitable, a resurgence of protections against such dangers must be guaranteed for its members.

\section{Notes}

1. For more on the concept 'ethnorace,' created in order to resist the black/white binary and do more justice to Latinx identities, see Alcoff (2005).

2. McMains notes that the greatest mambo musician, Tito Puente, 'always insisted he never played salsa - he ate salsa. He played mambo' (52). And her 'interview with Palladium mambo dancer Cuban Pete almost came to an impasse before it started because the release form I asked him to sign used the word "salsa" (53).

3. 'When neo-Marxism, feminist theory, poststructuralism, deconstructive methods, world systemic theory, and postcolonial writing (all of which I use in my writing) demand consistency, exclusivity, and royalties, they stop serving me' and 'become confining' (15).

4. I follow here Savigliano's rebellious grammatical practice in her text, strategically using feminine endings as gender-neutral in place of the masculine endings required by the grammatical rules of Spanish.

5. See Wittgenstein (1991).

6. On this note, at a recent conference, Thomas Defrantz suggested that I needed to add an eight, 'religious dance,' for dances such as those of the whirling dervishes. I am considering this suggestion carefully, and may well incorporate it in future work on this subject.

\section{Disclosure statement}

No potential conflict of interest was reported by the author.

\section{Notes on contributor}

Joshua M. Hall is Assistant Professor of Philosophy and Director of Liberal Studies at William Paterson University. His research focuses various historical and geographical lenses on philosophy's boundaries. This includes forty-six peer-reviewed journal articles (including in The Pluralist, Philosophy Compass, and Philosophy and Literature), ten anthology chapters (including in the forthcoming Dance and Philosophy), and editing with Sarah Tyson, Philosophy Imprisoned: The Love of Wisdom in the Age of Mass Incarceration.

\section{ORCID}

Joshua M. Hall (D) http://orcid.org/0000-0003-0762-6375 


\section{References}

Alcoff, L. M. 2005. Visible Identities: Race Gender and the Self. Oxford: Oxford University Press. Hall, J. M. 2021. "Dancing-with: A Theoretical Method for Poetic Social Justice." In Dance and Philosophy, edited by R. Farinas, J. C. Craig Hanks, V. Camp, and A. Bresnahan. London: Bloomsbury.

Hans-George Gadamer. 2004. Truth and Method, trans. Joel Weisenheimer \& Donald G. Marshall, 102. New York: Continuum.

.McMains, J. 2015. Spinning Mambo into Salsa: Caribbean Dance in Global Commerce. New York: Oxford.

Ross, V. R. 1958. Cosas de Negros: Estudios Preliminar y Notas de Horacio J. Becco. Buenos Aires: Hachette.

Savigliano, M. 1995. Tango and the Political Economy of Passion. Boulder, CO: Westview Press.

Thompson, R. F. 1973. "An Aesthetic of the Cool II." African Arts 7 (1): 40-92. doi:10.2307/ 3334749.

Wittgenstein, L. 1991. Philosophical Investigations. trans. G. E. M. Anscombe. Hoboken, NJ: Wiley-Blackwell. 